\title{
ОЦЕНКА ПОНИМАНИЯ ЭМОЦИЙ СОБЕСЕДНИКА ДЕТЬМИ С РЕЧЕВЫМИ НАРУШЕНИЯМИ
}

\section{ASSESSMENT OF THE UNDERSTANDING OF THE INTERLOCUTOR'S EMOTIONS BY CHILDREN WITH SPEECH DISORDERS}

\section{E. Troshina}

Summary: The article presents an analysis of the results of a study of the understanding of emotions and emotional manifestations of children with severe speech disorders (dysarthria and stuttering) in communication. The article theoretically substantiates and presents a methodology that includes an assessment of: the verbal designation of emotions, the definition of emotions of close friends, the designation of feelings and emotions in the assessment of pedagogical situations. The presented set of techniques made it possible to analyze the phenomenon of children's understanding of the emotions of the interlocutor and to determine its specific manifestations for children with dysarthria and stuttering, to determine the special educational needs of children with severe speech disorders in learning communication and adequate behavior in interaction. The results of the study can be a justification for differentiated correctional and developmental work on the social and communicative development of preschoolers with dysarthria and stuttering. Thus, understanding the emotions of the interlocutor as one of the most important aspects of the socialization of children with severe speech disorders, on the one hand, and research in this area, on the other, contribute to the successful social and communicative development of preschoolers with dysarthria and stuttering.

Keywords: social and communicative development, understanding of the interlocutor's emotions, language competence, communicative competence, speech disorders, dysarthria, stuttering.

\section{Актуальность}

$\mathrm{H}$ а сегодняшний день проблема понимания эмоций собеседника по общению детьми с тяжелыми нарушениями речи (THP) является одной из мало изученных. Способность верно понять чувства другого человека способствует развитию согласованности в общении, что содействует развитию компетентности в межличностных отношениях [3]. Наравне с этим, для детей с патологией речи характерно испытывать сложности распознавания и понимания эмоций партнера по общению, что в дальнейшем приводит к нарушению коммуникативного взаимодействия [9]. По замечанию О.Е. Грибовой [2], детям с ТНР тяжело установить, поддержать и завершить общение с окружающими людьми. Как отмечает И.Ю. Кондратенко [3], у детей с речевыми нарушениями умения выразить свои чувства словами, трошина Елена Сергеевна

ГАОУ ВО Ленинградской области «Ленинградский государственный университет им. А.С. Пушкина» elena-sveta27@mail.ru

Аннотация: В статье представлен анализ результатов исследования понимания эмоций и эмоциональных проявлений детей с тяжелыми нарушениями речи (дизартрией и заиканием) в общении. В статье теоретически обоснована и представлена методика, включающая оценку: вербального обозначения эмоций, определения эмоций близких друзей, обозначение чувств и эмоций при оценке педагогических ситуаций. Представленный комплекс методик позволил проанализировать феномен понимания детьми эмоций собеседника и определить его специфические проявления для детей с дизартрией и заиканием, определить особенные образовательные потребности детей с тяжелыми нарушениями речи в обучении общению и адекватному поведению во взаимодействии. Результаты исследования могут быть обоснованием дифференцированной коррекционно-развивающей работы по социально-коммуникативному развитию дошкольников с дизартрией и заиканием. Таким образом, понимание эмоций собеседника как одна из важнейших сторон социализации детей с тяжелыми нарушениями речи, с одной стороны, и исследование в данной области, с другой, способствуют успешному социально-коммуникативному развитию дошкольников с дизартрией и заиканием.

Ключевые слова: социально-коммуникативное развитие, понимание эмоций собеседника, языковая компетенция, коммуникативная компетенция, речевые нарушения, дизартрия, заикание.

распознавать и учитывать чувства других людей развиты не недостаточно. Таким образом, несформированность средств общения в целом и неумение распознавать эмоции окружающих в частности, могут стать главными причинами неблагоприятных отношений в группе сверстников [13]. Данное предположение подтверждают исследования, в которых указывается, что для детей с речевой патологией характерны трудности установления коммуникативных связей со взрослыми и сверстниками, приводящие к проблемам на пути развития и обучения [10]. Нарушения общения могут проявляться в неумении адекватно общаться с другими детьми, сложностях включения в общую деятельность, отказе от межличностных и групповых отношений. Соответственно, у детей с ТНР может отмечаться низкая адаптивность к условиям, в которых не присутствуют близкие, низкое восприятие общественных норм и социальных эталонов [8]. 
Одними из наиболее часто встречающихся в старшем дошкольном возрасте и различных по своей природе речевых нарушений являются дизартрия и заикание. В обоих случаях дети не могут выстроить полноценное общение со взрослыми и сверстниками, что связано с недостаточной сформированностью умения распознавать эмоции партнеров по общению.

Дети с дизартрией отличаются сниженной способностью к самоконтролю, вялым выражением и восприятием эмоций [6], застенчивостью, малообщительностью, нерешительностью [12]. Так, при дизартрии отмечается нарушение контактности [7], страх перед коллективом [5].

Детей с заиканием можно охарактеризовать как не желающих понимать свои собственные эмоции и эмоции окружающих [5]. При взаимоотношениях заикающихся с другими детьми проявляются не только положительные чувства (дружелюбие, добродушие), способствующие устойчивости общения, но и отрицательные (застенчивость, обидчивость, робость, негативное отношение к партнеру, протест, агрессия, аффективные переживания) [1].

Основываясь на вышесказанном, можно сказать о том, что значимая составляющая коммуникативного взаимодействия - умение понимать эмоции партнера по общению, у детей с дизартрией и заиканием развита не в полной мере. Так, несформированность умения распознавать эмоции собеседника у детей с дизартрией и заиканием, с одной стороны, и отсутствие единого диагностического инструментария в данной области для этих категорий детей, с другой, представляют значимой и актуальной работу по созданию и применению комплексной диагностической базы исследования понимания эмоций собеседника детьми с дизартрией и заиканием.

Таким образом, с целью оценки понимания эмоций собеседника дошкольниками с речевыми нарушениями, было проведено экспериментальное исследование. Экспериментальную выборку составили 90 дошкольников в возрасте от 6 до 7 лет (30 детей с дизартрией, 30 детей с заиканием, 30 детей с нормальным речевым развитием).

\section{Содержание}

Оценка феномена понимания эмоций собеседника включала: визуальную оценку эмоций виртуального собеседника; оценку эмоций собеседника при прослушивании текстов с эмоционально значимыми ситуациями; определение эмоциональных состояний участников коммуникации в виртуальной педагогической эмоционально окрашенной ситуации (по картинкам); понимание эмоций собеседника в реальной педагогической ситуации.

\section{1. Визуальная оценка эмоций виртуального собесеАника}

Методика применялась с целью оценки уровня понимания эмоций детей своей группы. Детям предлагались фотографии, на которых одногруппники находились в разных ситуациях общения и с различным выражением лица, отражающим десять базовых эмоций по К. Изарду [4] (интерес, радость, удивление, страдание, гнев, отвращение, презрение, страх, стыд, смущение). Детям предлагалось ответить на вопросы: «Кто изображён на фотографии? Как он себя чувствует? Как ты догадался об этом?». Критериями оценки явились: уровень сформированности умения определять эмоциональные состояния сверстника и объяснить свой ответ (проявление коммуникативной функции общения [11]); наиболее/ наименее узнаваемые эмоциональные состояния.

\section{2. Оченка эмоший собеседника при прослушивании текстов с эмоционально значимыми ситуашиями}

Целью методики являлась оценка способности распознавать и называть проявления эмоций при прослушивании и пересказе текста и понимания экспрессивных состояний рассказчика. Детям предлагалось внимательно послушать рассказ (разрешалось задавать вопросы в ходе прочтения), пересказать текст по наводящим вопросам. Оценивалось проявление эмпатии к героям рассказа, пересказ, соответствующий теме, активное использование лексики алфавита эмоций.

\section{3. Определение эмочиональных состояний участников коммуникашии в виртуальной пеАагогической эмошионально окрашенной ситуашии (по картинкам)}

Методика применялась с целью оценки уровня понимания чужого эмоционального состояния, умения его вербально обозначать и описывать. Ребенку предлагалось разложить картинки в нужном порядке (при необходимости оказывалась помощь взрослого), затем рассказать, что произошло. Оценивалось осмысливание ситуации детьми в форме истолкования и проявления эмпатии (точное определение эмоциональных состояний, «оречевление» персонажей, яркое эмоциональное отношение к изображенным героям).

\section{4. Понимание эмоший собеседника в реальной педагогической ситуашии}

Целью методики являлась оценка уровня понимания чужого эмоционального состояния, умение вербально его обозначать и описывать в рамках реальной педагогической ситуации. В ходе методики предполагалось активное использование детьми лексики алфавита эмо- 
ций, проявление понимания и эмпатии, яркого эмоционального отношения к участникам педагогической ситуации, самостоятельное осмысливание происходящего.

\section{ОбсужАение результатов}

По результатам исследования оценки понимания эмоций собеседника детьми с нормальным речевым развитием, дизартрией и заиканием был выявлен следующий уровень сформированности по вышеперечисленным методикам (рис.1).

Самые низкие показатели во всех исследуемых группах выявлены по методике изучения визуальной оценки эмоций (рис.2).

Как уже было сказано выше, детям предлагалось оценить базовые эмоции и их оттенки, однако наиболее узнаваемыми детьми как с нормальным речевым развитием, так и с речевой патологией стали такие эмоции как радость, грусть, удивление и страх. Распознавание этих четырех эмоций является нормой онтогенетического развития в старшем дошкольном возрасте, понимание остальных эмоций (рис.2) формируется позднее, что и объясняет самые низкие (по сравнению с другими методиками) результаты.

Детьми с нормальным речевым развитием был продемонстрирован высокий уровень понимания эмоций собеседника в рамках текста, в виртуальной и реальной педагогических ситуациях. Исключением явилась лишь визуальная оценка эмоций, где дошкольниками была показана недостаточная компетентность, что связано с возрастными особенностями развития. В группах детей с дизартрией и заиканием оценка эмоций по вышеперечисленным методикам вызвала значительные трудности, по сравнению с их сверстниками без патологии речи. Дошкольники с дизартрией несколько хуже детей с заиканием справились с оценкой эмоций одногруппников по фотографиям, что объясняется несформированностью словаря в области лексики алфавита эмоций, необходимого для вербализации эмоциональных состояний. С оценкой эмоций как в рамках текста, так и в рамках виртуальной педагогической ситуации дошкольники с дизартрией, напротив, справились успешнее сверстников с заиканием. Это связано с тем, что две данные методики иллюстрируют конкретные ситуации, а визуальная оценка эмоций является внеситуативной. Так, дошкольники с заиканием способны чувствовать и понимать эмоции внеситуативно, однако, в рамках коммуникативных ситуаций испытывают сложности. В то же время, дети с дизартрией демонстрируют более контактное поведение во взаимодействии, однако, для них характерны трудности вербализации эмоций, обусловленные недостаточным запасом эмотивной лексики. Эти факты указывают на нарушение языковой компетенции у детей с дизартрией и коммуникативной компетенции социально-коммуникативного развития у детей с заиканием. Однако, исследование понимания эмоций собеседника в рамках реальной педагогической ситуации показало самые низкие результаты в обеих экспериментальных группах. Это связано с тем, что несмотря на специфику коммуникативного развития в зависимости от характера речевого нарушения, дошкольники с патологией речи с трудом ориентируются в ситуации реального общения. И если в статических ситуациях (визуальная оценка, оценка в рамках текста, виртуальная педагогическая ситуация) дети проявляют понимание эмоций, то в динамическом реальном взаимодействии для них это является наиболее сложным, что и объясняет нарушения социально-коммуникативного развития у детей данных категорий.

Наравне с этим, представим специфические особенности детей с речевой патологией, выявленные в ходе проведения методик.

У детей с дизартрией определены следующие специфические особенности.

1. При визуальной оценке эмоций виртуального собеседника:

- неверное восприятие и объяснение эмоционального состояния (злость - она скучает, сидит и ничего не делает; отвращение - она обижена, глаза такие обиженные);

- использование слов с широким значением и высокой сочетаемостью (радость - хорошо; страх плохо; отвращение - не очень);

- отсутствие ответа, либо ответ «не знаю» (отсутствие ответа: страх, стыд, гнев; «не знаю»: грусть, скука, удивление);

- демонстрация позы или звукоподражание (поза: грусть, радость, стыд, гнев; звукоподражание: восхищение - он такой «ммм!»; удивление - такой «ооо!»; радость - такой «хия!»);

- штамповые объяснения: «по личу и глазам», «по виду, по картинке» (удовольствие - ей хорошо и весело, понял по личу; грусть - грустно, понял по картинке; удивление - удивительно, понял по виду; скука - плохо, по глазам);

- наличие аграмматизмов (рыдательно, ждательно).

2. При оценке эмоций собеседника при прослушивании текстов с эмоционально значимыми ситуациями (на примере рассказа Т.А. Ткаченко «Сердитый сторож»):

- грубые нарушения смысла рассказа (добавление несуществующих персонажей: сторож - это человек, пришли цыгане; несуществующих в рамках рассказа действий: Ваню поставили в угол);

- искажения эмоционального состояния героев рассказа (Ване не стыдно, а смешно; Ване стыдно 


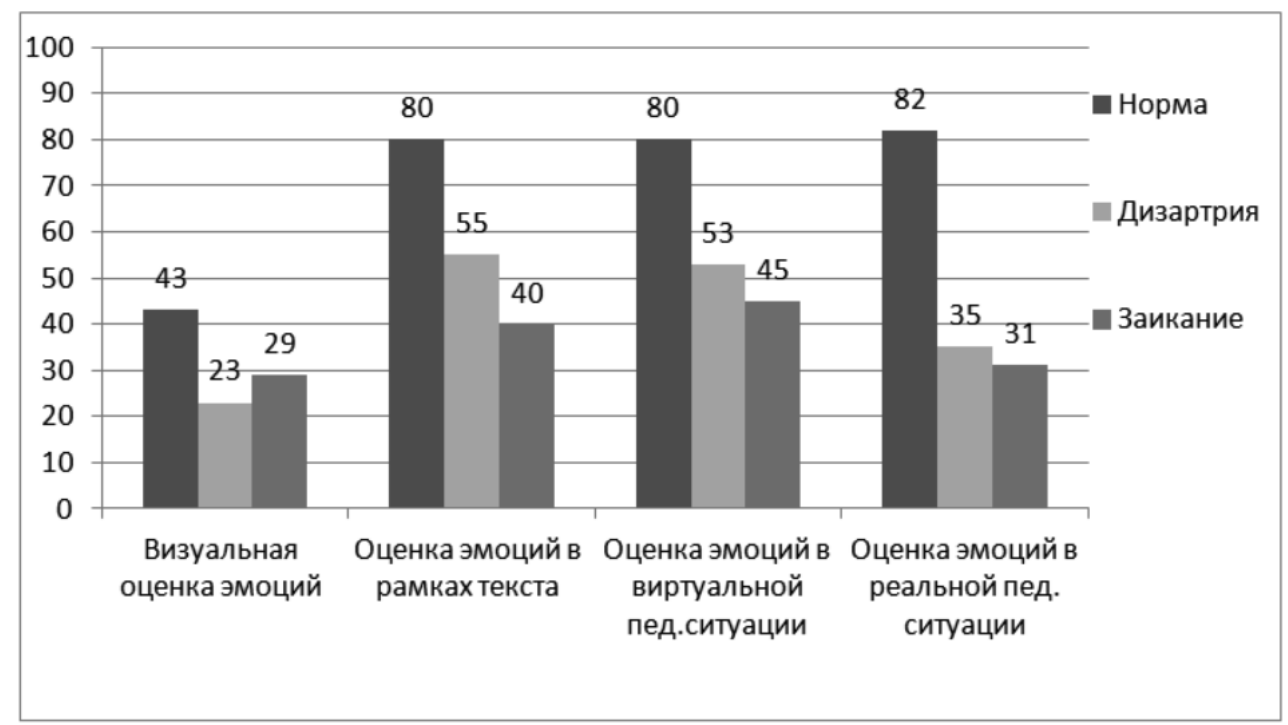

Рис.1. Уровень оценки феномена понимания эмоций собеседника детьми с нормальным речевым развитием, дизартрией и заиканием (в \%)

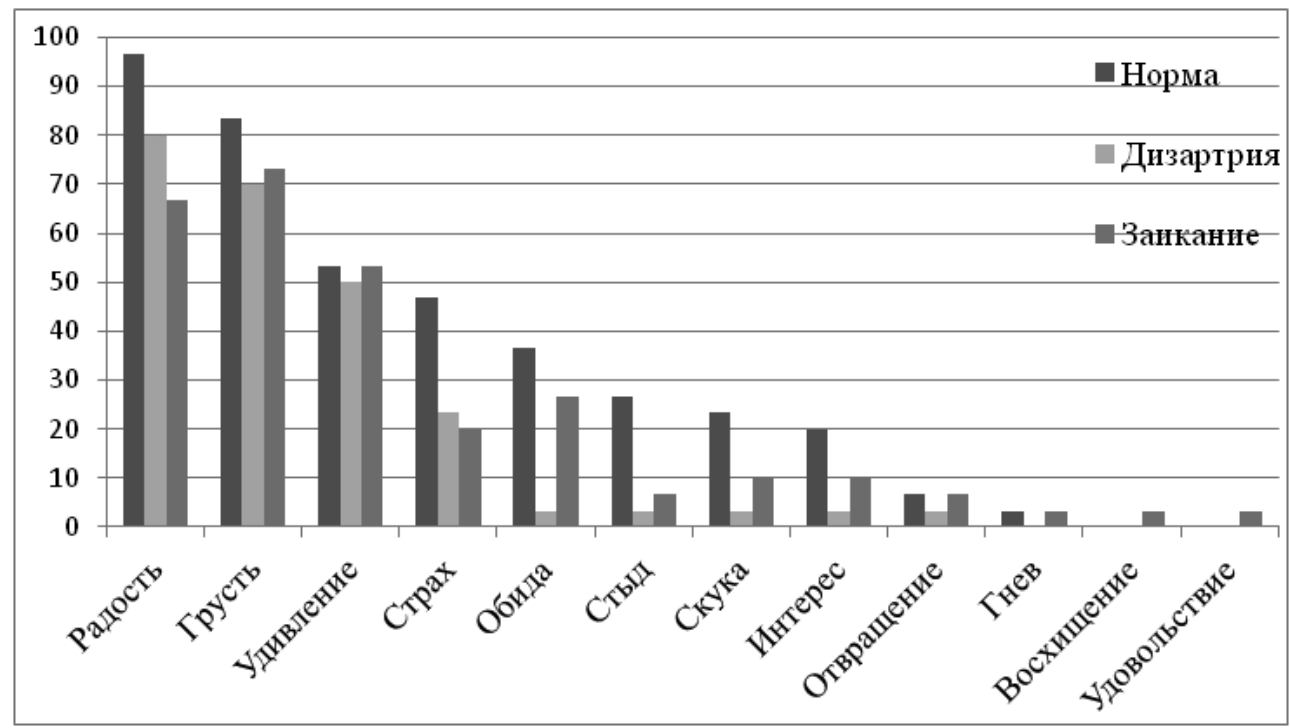

Рис.2. Частотность определения эмоциональных состояний сверстников по фотографиям детьми исследуемых групп (в \%)

не из-за поступка, а из-за смеха родителей).

\section{3. При определении эмоциональных состояний} участников коммуникации в виртуальной педагогической эмоционально окрашенной ситуации (на примере серии сюжетных картин к рассказу В.П. Катаева «Грибы»):

- вербализация эмоциональных состояний участников педагогической ситуации, изображенных на серии сюжетных картин, происходила по наводящим вопросам взрослого;

- склонность путать эмоциональные состояния участников педагогической ситуации - сходные (расстроилась - обиделась, злиться; расстроился - рассердился) и контрастные (грустная - веселая; веселая -грустная; обрадовалась - расстроилась);

- вербализация внешних признаков, а не эмоциональных состояний (девочка в горошек, желтая девочка, синяя девочка).

4. При понимании эмоций собеседника в реальной педагогической ситуации:

- трудности понимания смоделированной педагогической ситуации в целом;

- вербализация эмоционального состояния участников смоделированной педагогической ситуации происходила по наводящим вопросам взрослого; 
- трудности понимания и вербализации эмоциональных состояний участников смоделированной педагогической ситуации (ответы: не знаю, не понимаю; молчание);

- склонность путать эмоциональные состояния участников смоделированной педагогической ситуации - сходные (расстроился - очень обижен) и контрастные (грустная - радостная);

- описание внешних характеристик участников, а не эмоциональных состояний (мама красивая, мальчик маленький).

У детей с заиканием также были выявлены специфические особенности.

1. При визуальной оценке эмоций виртуального собеседника:

- неверное восприятие и объяснение эмоционального состояния (страх - удивительно, она такая задумчивая какая-то; интерес - грустит, потому что такой грустно смотрит; обида - она удивилась, у нее такие удивленные глаза);

- использование слов с широким значением и высокой сочетаемостью (грусть - плохо; радость хорошо; скука - нормально; отвращение - не очень хорошо);

- отсутствие ответа, либо ответ «не знаю» (отсутствие ответа: удивление, стыд, интерес; «не знаю»: удовольствие, гнев, скука);

- эмоциональные состояния перепутаны по положительной и отрицательной направленности (обида - радость; скука - интерес; обида - хорошо; восхищение - плохо);

- вместо эмоционального состояния названы личные ассоциации (обида - она плачет, не дали конфету или отняли игрушку).

2. При оценке эмоций собеседника при прослушивании текстов с эмоционально значимыми ситуациями (на примере рассказа Т.А. Ткаченко «Сердитый сторож»):

- грубые нарушения смысла рассказа (ночью родители легли сnать; была еще и дочка);

- искажения эмоционального состояния героев рассказа (когда папа ругался, Ваня засмеялся, а мама испугалась; Ваня чувствовал себя плохо, но отправился за ягодами);

- склонность путать эмоциональные состояния сходные и контрастные (стыдно - волнительно, сердито, обидно; стыдно - смешно).

3. При определении эмоциональных состояний участников коммуникации в виртуальной педагогической эмоционально окрашенной ситуации (на примере серии сюжетных картин к рассказу В.П. Катаева «Грибы»):
- вербализация эмоциональных состояний участников педагогической ситуации, изображенных на серии сюжетных картин, происходила по наводящим вопросам взрослого;

- склонность путать эмоциональные состояния участников педагогической ситуации - сходные (расстроился - сердитый, рассердился; удивилась - обиделась; расстроилась - задумчивое настроение) и контрастные (расстроилась - веселая, хорошее настроение);

- искажения и неточности при описании эмоциональных состояний участников педагогической ситуации (девочка принесла мухоморы, а мама хорошо себя чувствует).

4. При понимании эмоций собеседника в реальной педагогической ситуации:

- трудности понимания смоделированной педагогической ситуации в целом;

- вербализация эмоционального состояния участников смоделированной педагогической ситуации происходила по наводящим вопросам взрослого;

- трудности понимания и вербализации эмоциональных состояний участников смоделированной педагогической ситуации (ответы: не знаю, не понимаю; молчание);

- склонность путать эмоциональные состояния участников смоделированной педагогической ситуации - сходные (расстроился - рассердился) и контрастные (веселится - грустит);

- описание внешних характеристик участников, а не эмоциональных состояний (у мамы и девочки красивые платья);

- искажения и неточности при описании эмоциональных состояний участников смоделированной педагогической ситуации (девочка плачеm, nomoму что она мухомор съела; мама и девочка заплакали).

Анализ рангового коэффициента корреляции Спирмена в группах дошкольников с речевой патологией показал ряд корреляционных зависимостей.

В группе детей с дизартрией выявлена взаимосвязь между достаточным словарным запасом в области лексики алфавита эмоций и способностью распознать и верно назвать эмоциональное состояние, а также между пониманием и вербализацией ребенком эмоционального состояния знакомого сверстника по фотографии и способностью объяснить и аргументировать свой ответ. Наравне с этим было определено, что чем более успешно ребенок справился с визуальной оценкой эмоций, тем более успешно он и пересказал эмоционально насыщенный текст. Помимо того, если ребенок успешно выполнил задания методики, направленной на опреде- 
ление эмоциональных состояний в виртуальной педагогической эмоционально окрашенной ситуации, тем легче ему было справиться с визуальной оценкой эмоций.

В группе детей с заиканием была выявлена взаимосвязь между пониманием и вербализацией ребенком эмоционального состояния знакомого сверстника по фотографии и способностью объяснить и аргументировать свой ответ. Также определено, что достаточный словарный запас в области лексики алфавита эмоций позволяет более успешно понимать и называть эмоциональные состояния одногруппников.

Таким образом, основываясь на вышесказанном можно сделать следующие выводы:

1. Дошкольники с нормальным речевым развитием справились с оценкой понимания эмоций собеседника по исследуемым параметрам значительно успешнее сверстников с речевой патологией.

2. Дошкольники всех исследуемых групп наименее успешно справились с визуальной оценкой эмоций знакомых сверстников по фотографиям, определив лишь четыре базовых эмоции (радость, грусть, удивление, страх), что является допустимым и не противоречит нормам онтогенетического развития.

3. Дошкольники с дизартрией несколько успешнее сверстников с заиканием справились с оценкой эмоций собеседника в рамках текста и виртуальной педагогической ситуации, предусматривающих коммуникативное взаимодействие. Исключением явилась визуальная оценка эмоций, предполагающая актуализацию лексики алфавита эмоций, где дошкольниками с заиканием были продемонстрированы более высокие результаты в сравнении с детьми с дизартрией. Это обусловлено характером речевого нарушения и, как следствие, нарушением языковой компетенции социально-коммуникативного развития у детей с дизартрией и коммуникативной у детей с заиканием.

4. У дошкольников обеих экспериментальных групп были выявлены самые низкие показатели по результатам исследования оценки ими реальной педагогической ситуации. Так, дети с нарушениями речи испытывают сложности в реальном коммуникативном взаимодействии, что впоследствии может привести к трудностям общения со взрослыми и сверстниками.

5. Выявленные специфические особенности в обеих экспериментальных группах позволяют более углубленно рассмотреть природу оценки эмоций детьми как с дизартрией, так и с заиканием, что в дальнейшем способствует более точной дифференциации в коррекционно-развивающей работе с детьми данных категорий.

6. Большее количество корреляционных зависимостей в группе дошкольников с дизартрией в сравнении с их сверстниками с заиканием свидетельствует о более высокой зрелости понимания эмоций собеседника, что соотносится с показателями по выполнению вышеперечисленных методик.

\section{ЗакАючение}

На основе результатов исследования представленного комплекса методик, выявлен и проанализирован феномен понимания эмоций собеседника детьми с дизартрией и заиканием. Таким образом, значимой и актуальной представляется дифференцированная коррекционноразвивающая работа по развитию навыков понимания эмоций собеседника детьми с речевыми нарушениями, включающая такие направления как визуальная и аудио оценка эмоций, а также оценка эмоциональных состояний в рамках виртуальных педагогических ситуаций и в реальном коммуникативном взаимодействии. Результаты проведенного исследования также могут быть положены в основу практических рекомендаций для учителей-логопедов, учителей-дефектологов, воспитателей и родителей. Так, проведенное исследование может способствовать совершенствованию практики обучения и воспитания детей с дизартрией и заиканием.

\section{ЛИТЕРАТУРА}

1. Волкова Г.А. Особенности эмоционально-волевой сферы и произвольной регуляции деятельности детей с заиканием и дизартрией / Г.А. Волкова // Логопед. - 2012. - №6. - С. 18-28.

2. рибова 0.Е. К проблеме анализа коммуникации у детей с речевой патологией / 0.Е. Грибова // Дефектология. - 1995. - № 6 - С. 7 - 16.

3. Кондратенко И.Ю. Формирование эмоциональной лексики у дошкольников с общим недоразвитием речи: Монография / И.Ю. Кондратенко. - СПб.: KAP0, 2006. $-240 \mathrm{c}$.

4. Кәрролл Э. Изард. Психология эмоций / Э. Изард Кэролл. - СПб: Изд-во: Питер, 2000 - 464 с.

5. Логопедия: учебник для студентов дефектол. фак. пед. вузов / Под ред. Л.С. Волковой, С.Н. Шаховской. - М.: Гуманит. изд. центр ВЛАДОС, $1998 .-680$ с.

6. Мартынова Р.И. 0 психолого-педагогических особенностях детей дислаликов и дизартриков / Р.И. Мартынова // Очерки по патологии речи и голоса. 1967. - № 3. - C. 98-111. 
7. Мартынова Р.И. Сравнительная характеристика детей, страдающих легкими формами дизартрии и функциональной дислалии. // Расстройства речи и методы их устранения. / Под ред. С.С. Ляпидевского С.Н. Шаховской. - М., 1975.

8. Никифорова Е.В. Развитие социальных эмоций у детей дошкольного возраста, имеющих нарушения общения со сверстниками / Е.В. Никифорова // Дефектология. - 1997. - № 3-С. 57 - 62.

9. Овчинникова Т.С. Распознавание эмоций в музыке и речи дошкольниками с речевыми нарушениями / Т.С. Овчинникова // Обучение, адаптация и интеграция детей с нарушениями развития. - СПб.: Образование, 1995. - С. 156-157.

10. Основы специальной психологии: учеб. пособие для студ. сред. пед. учеб, заведений / Под ред. Л.В. Кузнецовой. - М: изд. Центр Академия, 2005 - 480 с.

11. Панферов В.Н. Классификация функций человека как субъекта общения / В.Н. Панферов // Социальная психология в трудах отечественных психологов / Сост. А.Л. Свенцицкий. - СПб: Питер, 2000. - 512 с.

12. Правдина 0.В. Дизартрия. Расстройства речи и методы их устранения: В 2 т. /0.В. Правдина под ред. Л.С. Волковой и В.И. Селиверстова. - Москва: Владос, 1997. - Т. 1. - 560 с.

13. Слинько 0.А. К изучению проблемы межличностных отношений дошкольников с нарушениями речи / 0.А. Слинько // Дефектология. - 1992. - № 1. C. 62-67.

(c) Трошина Елена Сергеевна (elena-sveta27@mail.ru).

Журнал «Современная наука: актуальные проблемы теории и практики»

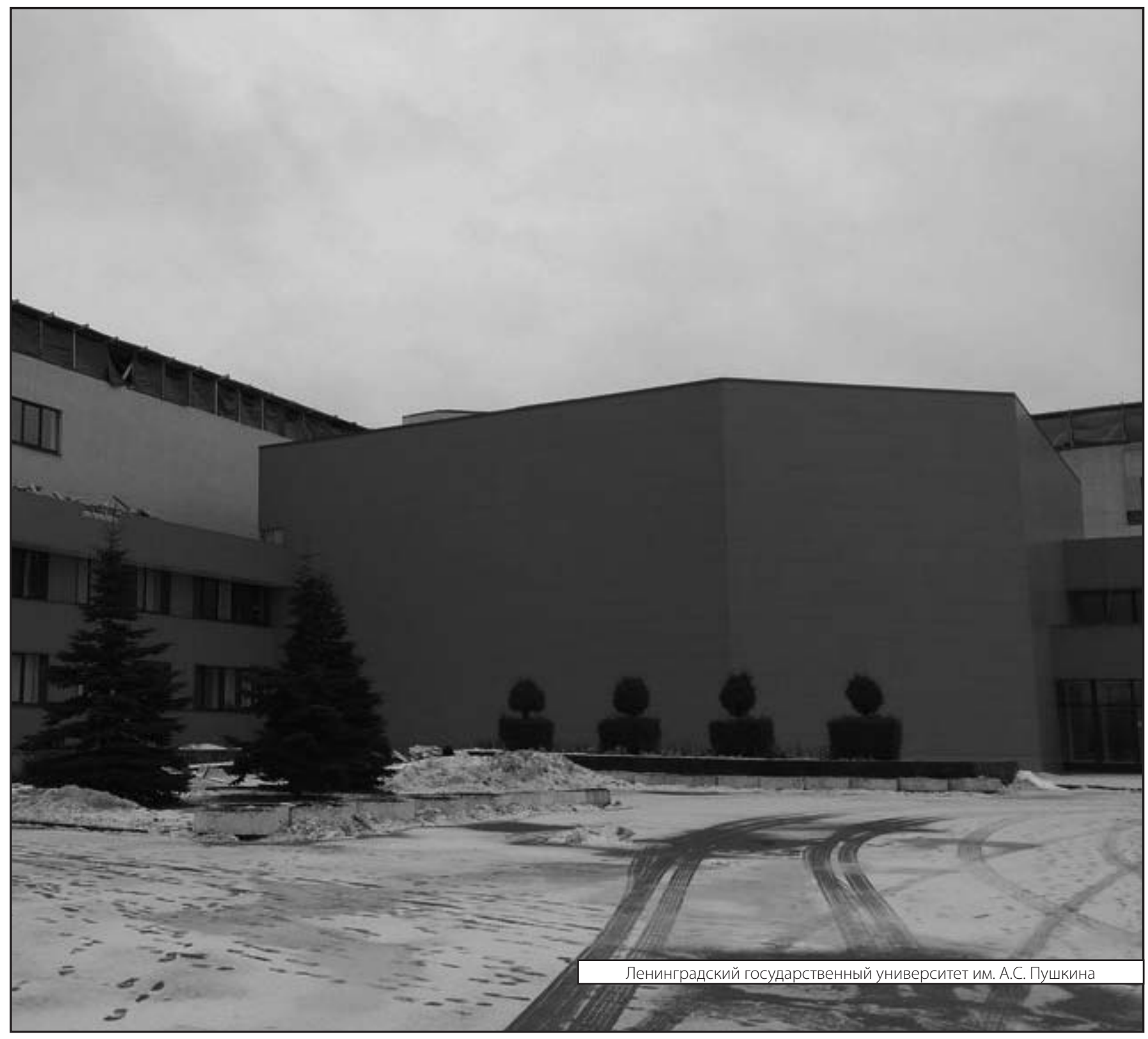

